\title{
List of abbreviations
}

$\begin{array}{ll}\text { ABM } & \text { Anti-ballistic missile } \\ \text { AFL } & \text { American Federation of Labor } \\ \text { ANC } & \text { African National Congress } \\ \text { ANF } & \text { Atlantic nuclear force } \\ \text { BBC } & \text { British Broadcasting Corporation } \\ \text { CAP } & \text { Common Agricultural Policy (of the EC) } \\ \text { CIA } & \text { Central Intelligence Agency } \\ \text { CLPD } & \text { Campaign for Labour Party Democracy } \\ \text { CND } & \text { Campaign for Nuclear Disarmament } \\ \text { CPGB } & \text { Communist Party of Great Britain } \\ \text { CSCE } & \text { Conference for Security and Cooperation in Europe } \\ \text { DFID } & \text { Department for International Development } \\ \text { EC } & \text { European Community } \\ \text { EEC } & \text { European Economic Community } \\ \text { EFTA } & \text { European Free Trade Association } \\ \text { END } & \text { European Nuclear Disarmament } \\ \text { ERM } & \text { Exchange Rate Mechanism } \\ \text { EU } & \text { European Union } \\ \text { FCO } & \text { Foreign and Commonwealth Office } \\ \text { G-8 } & \text { Group of 8 Industrialised Nations } \\ \text { GNP } & \text { Gross National Product } \\ \text { HC Deb } & \text { House of Commons Debates (Hansard) } \\ \text { HIPC } & \text { Heavily Indebted Poor Countries } \\ \text { ILP } & \text { Independent Labour Party } \\ \text { IMF } & \text { International Monetary Fund } \\ \text { INF } & \text { Intermediate-range Nuclear Forces } \\ \text { ISAF } & \text { Labour Party Annual Conference Report } \\ \text { LPACR } & \end{array}$


MEP

MLF

MOD

MP

MRC

NATO

NEC

PLO

PLP

PRO

SALT

SDP

SDR

START II

SWAPO

TGWU

TNA

TUC

TUCR

UDI

UN

UNESCO

UNSCOM

WEU

WMD

ZANU

ZAPU
Member of European Parliament

Multilateral Force

Ministry of Defence

Member of Parliament

Modern Records Centre

North Atlantic Treaty Organisation

National Executive Committee (Labour Party)

Palestinian Liberation Organisation

Parliamentary Labour Party

Public Record Office

I \& II Strategic Arms Limitations Talks

Social Democratic Party

Strategic Defence Review

Strategic Arms Reduction Treaty

South West Africa People's Organisation

Transport and General Workers' Union

The National Archives (previously known as the

Public Record Office)

Trades Union Congress

Trades Union Congress Annual Report

Unilateral Declaration of Independence (Southern

Rhodesia)

United Nations

United Nations Education, Scientific and Cultural Organisation

United Nations Special Commission

Western European Union

weapons of mass destruction

Zimbabwe African National Union

Zimbabwe African People's Union 